http://jmscr.igmpublication.org/home/ ISSN (e)-2347-176x ISSN (p) 2455-0450 crossref DOI: https://dx.doi.org/10.18535/jmscr/v9i1.17

\author{
Journal Of Medical Science And Clinical Research \\ IGM Publication \\ An official Publication of IGM Publication
}

\title{
Study of Morphological variations of Left Coronary Artery in Human cadaveric hearts
}

\author{
Author
}

Dr C. P. Anbarasi

Senior Assistant Professor, Department of Anatomy, Government Thiruvannamalai Medical College, Tamil

Nadu, India

Corresponding Author

Dr C. P. Anbarasi

\begin{abstract}
Background: The arterial supply to the heart is provided by the coronary arteries which are the branches of the Ascending aorta. Variation in the origin, course and branching pattern of left coronary artery affect the blood supply to the heart. Knowledge of variations in the morphology of Left Coronary artery is useful for Cardiologists and Cardiothoracic Surgeons for angiographic interpretation and Stenting Procedures.

Materials and Methods: 50 Heart specimens were examined in the Institute of Anatomy, Madurai medical college, Madurai.

Results: In the present study conducted in 50 specimens, left coronary ostia found in left posterior aortic sinus in all 50 specimens (100\%). Level of ostium below the sinotubular junction (94\%), above STJ (4\%) and at STJ (2\%). Length of the main trunk $\leq 5 \mathrm{~mm}$ (14\%), 6 to $10 \mathrm{~mm}(64 \%), 11$ to $15 \mathrm{~mm}(20 \%)$ and 16 to $20 \mathrm{~mm}(2 \%)$.

Conclusion: Variations in the location, level of ostium and length of main trunk of left coronary artery help the clinicians for performing angiography and angioplasty.

Keywords: Left coronary artery, left coronary ostia, sinotubular junction, length of main trunk.
\end{abstract}

\section{Introduction}

Coronary circulation is the circulation of blood in the blood vessels of the heart. Coronary arteries are the vessels that supply oxygen rich blood to the myocardium. These narrow vessels are commonly affected by atherosclerosis, can be obstructed leading to angina or heart $\operatorname{attack}^{(1)}$. Coronary blood flow in Humans at rest is about $225-250 \mathrm{ml} / \mathrm{min}$, about $5 \%$ of cardiac output ${ }^{(2)}$. Coronary arteriography remains the standard for identifying the presence or absence of arterial narrowing related atherosclerotic coronary artery disease and provides the most reliable anatomic information for determining the appropriateness of medical therapy, percutaneous coronary intervention, coronary artery bypass grafting in patients with ischemic coronary artery disease ${ }^{(3)}$. Variation in the origin, course and distribution of the epicardial coronary arteries are found in 1-2 $\%$ of population. Certain types of anomalies include ostial lesions, passage of major artery between the walls of pulmonary trunk, a major coronary artery originates from pulmonary trunk or perhaps myocardial bridges may produce ischemia and subsequent myocardial infarction ${ }^{(4)}$ 
Procedures like coronary angiography, angioplasty and coronary artery bypass grafting are done in coronary arteries. Knowledge of the variations in coronary arteries is essential for the Cardiothoracic surgeons and Interventional radiologist for avoiding inadvertent vascular trauma during the procedures. This study was done to know the prevalence of variations in South Indian population.

\section{Materials \& Methods}

Source of data: The study was carried out in 50 adult Human hearts. These specimens were dissected and studied over a period of two years

Study Design: Cross sectional study.

Sample size: 50 Human heart specimens.

Steps of Dissection: The specimen collected was washed thoroughly in running tap water and later dissected, thoroughly examined after which they are preserved in solution containing 1 litre of $10 \%$ formalin, $50 \mathrm{ml}$ of glycerine, 10 litre of normal saline and 5 gms of powdered thymol. During the study, the visceral pericardium was stripped off, the left coronary artery originating from the ascending aorta from its Left Posterior Aortic Sinus (LPAS) identified and its course traced.

Inclusion Criteria: Formalin fixed heart specimens with intact coronary arteries irrespective of age, sex and race.

Exclusion Criteria: Hearts which were grossly mutilated and decomposed were excluded from this study.

\section{Results}

This present study of morphology of Left coronary artery (LCA) in fifty specimens reveals the following results:

\section{Location of ostium}

The ostium of left coronary artery in this study was seen in left posterior aortic sinus in all fifty specimens $(100 \%)$.

\section{Level of ostium with relation to Sino tubular Junction (STJ) \\ (Table 1)}

In the present study, ostium of the left coronary artery was noted with relation to STJ.

Table-1: Level of ostium with relation to sinotubular junction

\begin{tabular}{|l|c|c|}
\hline Position of ostium & Frequency & Percentage \\
\hline Above & 2 & $4 \%$ \\
\hline At & 1 & $2 \%$ \\
\hline Below & 47 & $94 \%$ \\
\hline Total & 50 & $100 \%$ \\
\hline
\end{tabular}

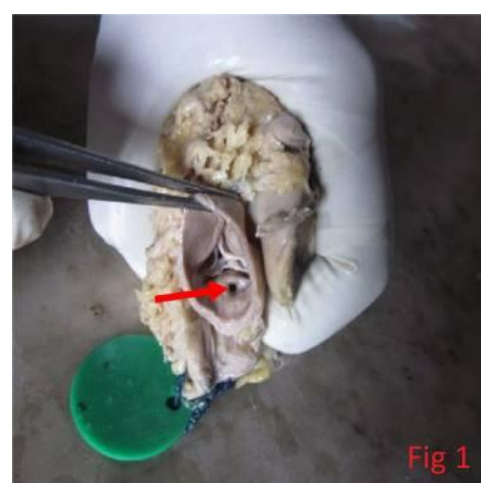

Fig 1: Location of ostium above STJ

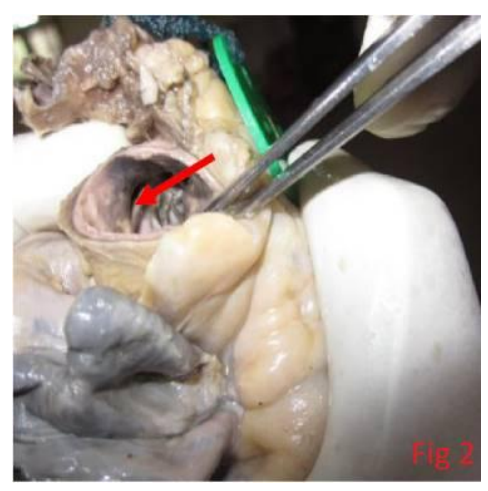

Fig 2: At the level of STJ

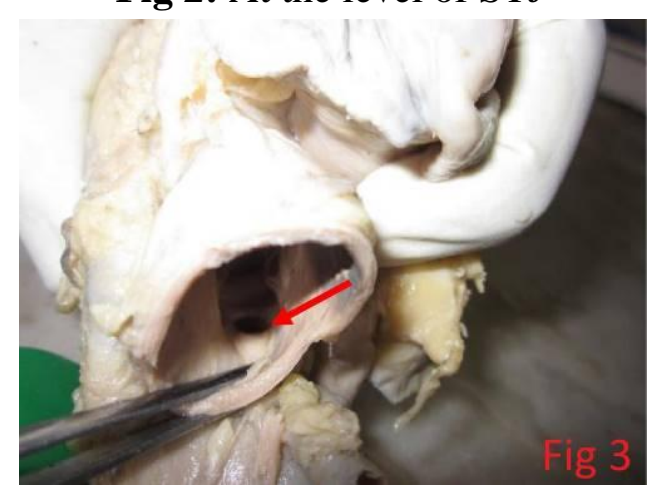

Fig 3: Below STJ

\section{Length of main trunk (Table 2)}

In this study, trunk of left main coronary artery was measured. The mean length was about $8.42 \pm$ $2.3 \mathrm{~mm}$. The minimum length was $3 \mathrm{~mm}$ (as shown in Fig 4). The maximum length was $16 \mathrm{~mm}$ (as shown in Fig 5). 
Table-2: Length of main trunk

\begin{tabular}{|l|c|c|}
\hline $\begin{array}{l}\text { Length of main } \\
\text { trunk }(\mathbf{m m})\end{array}$ & Frequency & Percentage \\
\hline$\leq 5 \mathrm{~mm}$ & 7 & $14 \%$ \\
\hline $6-10 \mathrm{~mm}$ & 32 & $64 \%$ \\
\hline $11-15 \mathrm{~mm}$ & 10 & $20 \%$ \\
\hline $16-20 \mathrm{~mm}$ & 1 & $2 \%$ \\
\hline Total & 50 & $100 \%$ \\
\hline
\end{tabular}

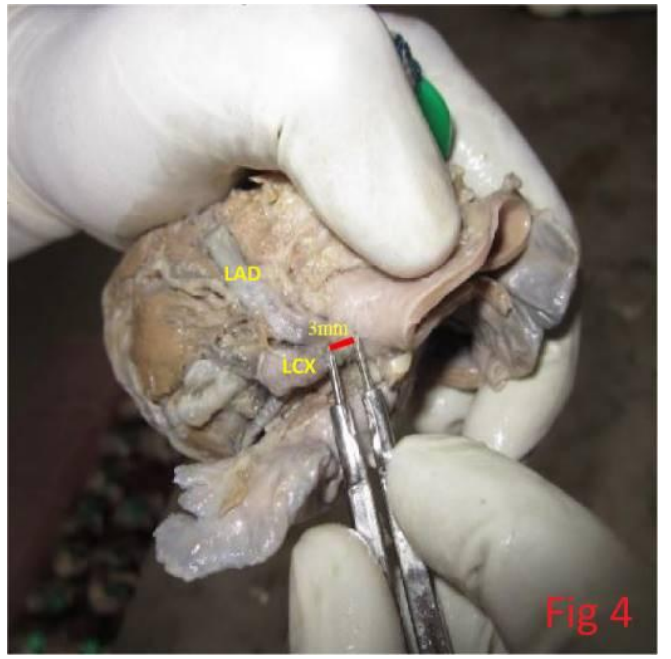

Fig 4: Short trunk of LCA

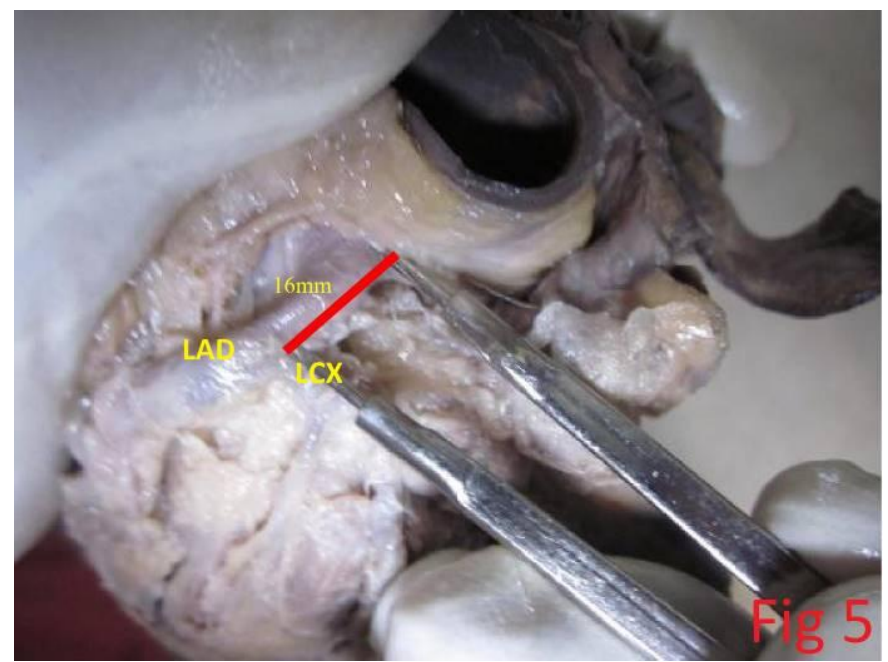

Fig 5: Long trunk of LCA

\section{Discussion}

\section{Location of ostium}

Aortic sinus is the anatomic dilatation of the ascending aorta which is seen just above the aortic valve. Left coronary artery ostium is commonly seen in left posterior aortic sinus. If the LCA takes origin from the right cusp, then it passes between the Aorta and pulmonary trunk. This segment is subjected to compression during heavy exercise can cause sudden death in athletes and young persons. Such origin is called as malignant left coronary artery.

\section{Level of ostium with relation to Sinotubular junction (Table-3)}

Location of coronary ostium is described in terms of their relation to the sinotubular junction. Manipulating catheter tips will be difficult if the ostium is located above the level of STJ which is called as high take off of LCA. Blood flow in coronary arteries only during diastole of the ventricle if ostium are below the STJ as the ostium is closed by cusps of the valve. But if the ostia are above the STJ, they remain open in both systole and diastole of the heart and coronary blood flows continuously. So such individuals suffer less from coronary insufficiency and asked less for angiography ${ }^{(8)}$.Comparison of the results of the present study with results of various other authors is as follows.

Table- 3: Comparison of level of ostium with relation to STJ

\begin{tabular}{|c|c|c|c|c|}
\hline S. No & Author & Below & At & Above \\
\hline 1. & $\begin{array}{l}\text { Kalpana } \\
2003(5)\end{array}$ & $80 \%$ & $20 \%$ & $0 \%$ \\
\hline 2. & $\begin{array}{l}\text { Dattatray } \\
2012(7)\end{array}$ & $79.7 \%$ & $17.2 \%$ & $3.1 \%$ \\
\hline 3. & $\begin{array}{c}\text { Prajapathi } \\
2013(8)\end{array}$ & $94 \%$ & $0 \%$ & $6 \%$ \\
\hline 4. & $\begin{array}{c}\text { Tomar } \\
2013(10)\end{array}$ & $84 \%$ & $14 \%$ & $2 \%$ \\
\hline 5. & $\begin{array}{c}\text { Present } \\
\text { study } 2015\end{array}$ & $94 \%$ & $2 \%$ & $4 \%$ \\
\hline
\end{tabular}

The difference in percentage could be due to difference in sample size and difference in racial $\&$ geographical population.

\section{Length of Main Trunk}

Normal length of main trunk has been found to range between 1-26 mm. The short main trunk of LCA explains some failures of adequate coronary perfusion.

A short main trunk of LCA results in a small pressure drop and a large flow at the bifurcation. The resulting high wall shear favours atherogenesis at the bifurcation and in the 
proximal segments of LAD and LCX arteries. Unusually short trunk $(<6 \mathrm{~mm})$ predisposes to Left bundle branch block $^{(10)}$. Coronary angiography is difficult if the length of main trunk is short because when catheter is inserted into one of the terminal branch, the opacification of the other branch does not occur and coronary tree image will be incomplete

Table-4: Results of previous studies, A Review of Literature

\begin{tabular}{|l|c|c|c|}
\hline S.no & Author & $\begin{array}{c}\text { Year of } \\
\text { study }\end{array}$ & $\begin{array}{c}\text { Mean length of } \\
\text { LMCA }\end{array}$ \\
\hline 1 & Kalpana (5) & 2003 & $9.9 \pm 4.15 \mathrm{~mm}$ \\
\hline 2 & Tomar (!0) & 2013 & $7.2 \pm 3.04 \mathrm{~mm}$ \\
\hline 3 & $\begin{array}{c}\text { Sanchita } \\
\text { Roy(9) }\end{array}$ & 2014 & $11.2 \pm 5 \mathrm{~mm}$ \\
\hline 4 & Present study & 2015 & $8.4 \pm 2.3 \mathrm{~mm}$ \\
\hline
\end{tabular}

\section{Conclusion}

The number, location, level and size of the ostium are very important in successful performance of coronary angiography. This study would help in preventing diagnostic errors and interpretation of such anomalies in many investigative procedures like angiogram. The advances made in modern methods of myocardial revascularization makes it imperative that thorough knowledge of the normal and variant anatomy of the LCA is required which led to the current study.

\section{Acknowledgements}

I wish to express my sincere thanks to Dr. Vidhulatha, Assistant Professor, Institute of Anatomy, Madurai Medical College for her encouragement and help extended during this study.

\section{References}

1. CC-BY book.open stax college, Anatomy \& Physiology. open stax CNX.30 jul 2014.

2. Arch Mal Coeur Vaiss, 1983, feb;76 spec no: 7-12 (NCBI).

3. Braunwald's Heart disease 10th Edition January 2015 Volume- 1, Page-1
4. Hurst, Hurst's The Heart Foster O' Kourke, Walsh Poole-Wilson,2008,12th edition,pg.19-20.

5. Kalpana R.2003. A study of principal branches of coronary arteries in humans. $\mathrm{J}$ Anat soc. India. 52 (2): 137-40

6. Pejkovic B et al, Anatomical variations of coronary ostia, Aorta coronary angles and Angles of division of the left coronary artery of the human heart. JIMR 2008;36:914-922.

7. Dattatray D. Dombe, et al,2012,clinically relevant morphometric analysis of left coronary artery. Int J Bio Med Res.3(1):1327-1330

8. Prajapati et al, variations in ostium of coronary arteries. National journal of medical research vol 3, issue 2,2013.

9. Sanchita Roy et al: Morphometric study of left coronary artery trunk in adult human cadavers: A study on eastern population. Journal of clinical and Diagnostic Research, 2014 feb,vol-8(2):7-9

10. Tomar $\mathrm{S}$ et al: Normal and variant anatomy of Left coronary Artery: 64-slice Multi Detector Computed Tomography (MDCT). Coronary Angiographic Depiction in North Indian population. IJSRP, volume 3, issue 8, August 2013.

\section{Abbreviations}

LCA - Left coronary artery.

LPAS - Left posterior aortic sinus

STJ - Sino tubular junction.

LAD - Left Anterior Descending artery

LCX - Left Circumflex artery 